\title{
Prevalence of hepatitis $C$ virus infection among prisoners in Iran: a systematic review and meta-analysis
}

\author{
Masoud Behzadifar ${ }^{1}$, Hasan Abolghasem Gorji ${ }^{2^{*}}$, Aziz Rezapour² and Nicola Luigi Bragazzi ${ }^{3}$
}

\begin{abstract}
Background: Hepatitis C virus (HCV) is one of the major public health problems both in developed and developing countries. Prison represents a high-risk environment for prisoners, in that it is characterized by high-risk behaviors such as injecting drug use (IDU), tattooing, unprotected sexual intercourses, or sharing syringes. The aim of this study was to quantitatively evaluate the prevalence of HCV among Iranian prisoners conducting a systematic review and meta-analysis.

Methods: We searched different scholarly databases including Embase, PubMed/MEDLINE, ISI/Web of Sciences, the Cochrane library, Scopus, CINAHL, and PsycINFO as well as Iranian bibliographic thesauri (namely, Barakatns, Maglran, and SID) up to December 2017. The Newcastle Ottawa Scale (NOS) was used to assess the quality of the studies included. HCV prevalence rate with its 95\% confidence interval (CI) was estimated using the DerSimonian-Laird random-effects model, with Freeman-Tukey double arcsine transformation. Egger's regression test was used to evaluate publication bias.
\end{abstract}

Results: Finally, 17 articles were selected based on inclusion and exclusion criteria. Overall, 18,693 prisoners were tested. Based on the random-effects model, the prevalence of HCV among Iranian prisoners was 28\% (Cl 95\% 2136) with heterogeneity of $P^{2}=99.3 \%(p=0.00)$. All studies used an ELISA test for the evaluation of HCV antibodies. The findings of this study showed that the highest prevalence rate (53\%) was among prisoners who inject drugs.

Conclusion: The findings of our study showed that the prevalence of HCV among Iranian prisoners is dramatically high. Managing this issue in Iran's prisons requires careful attention to the availability of health facilities and instruments, such as screening, and harm reduction policies, such as giving sterile syringes and needles to prisoners. An integrated program of training for prisoners, prison personnel and medical staff is also needed to improve the level of health condition in prisons.

Keywords: Hepatitis C virus, Prevalence, Prisoners, Iran, Meta-analysis, Systematic review

\section{Background}

Hepatitis $\mathrm{C}$ virus $(\mathrm{HCV})$ is one of the major public health problems both in developed and developing countries, leading to acute and chronic hepatitis [1]. It is estimated that 71 million people in the world are suffering from chronic HCV, and about 399,000 people die each year due to cirrhosis and liver cancer [2]. The prevalence of $\mathrm{HCV}$ has been computed to be approximately $0.6 \%$ in the

\footnotetext{
* Correspondence: gorjiha@yahoo.com

${ }^{2}$ Health Management and Economics Research Center, Iran University of

Medical Sciences, Tehran, Iran

Full list of author information is available at the end of the article
}

general population [3] and $0.5 \%$ among blood donors in Iran [4].

Prison represents a high-risk environment for prisoners, in that it is characterized by risky behaviors such as injecting drug use (IDU), tattooing, unprotected sexual intercourses, or sharing syringes. For example, IDU represents a major risk factor, with $52 \%$ of 11.7 million people injecting drugs worldwide living with $\mathrm{HCV}$ [5]. Furthermore, inadequate access to preventive interventions and diagnostic measures increases the risk of transmitting infections. $\mathrm{HCV}$, like other pathogens, such as hepatitis B virus (HBV) and human immunodeficiency virus (HIV), is 
transmitted through blood [6, 7]. HCV infection represents the main cause of liver cancer and can affect the outcome of liver transplantation [8,9]. Liver disease is a major cause of death among inmates and has recently surpassed HIV. Compared to other subjects, prisoners are more likely to develop HCV and to die of its complications [10-12].

According to the latest data available from the "Global State of Harm Reduction" report and to a comprehensive review of the global disease burden in prisoners, it has been estimated that approximately $15.1 \%$ of 10.2 million people incarcerated at any given time are living with $\operatorname{HCV}[5,13]$. More in detail, several studies have been conducted to determine the prevalence of $\mathrm{HCV}$ worldwide, reporting different findings. For example, 22. 7\% of prisoners in Spain [14], 6.9\% in Sri Lanka [15], 17. $7 \%$ in Turkey [16], 2.4\% in Brazil [17], and $10.1 \%$ in the USA [18] have been found to suffer from HCV infection.

Precise epidemiological figures related $\mathrm{HCV}$ prevalence are fundamental in the health sector for policyand decision-makers in each country to inform health policies in an evidence-based way [19]. In recent years, research has been conducted to determine the prevalence of $\mathrm{HCV}$ in Iran in order to estimate $\mathrm{HCV}$ infection among prisoners. The knowledge of the epidemiology of $\mathrm{HCV}$ among Iranian prisoners can effectively guide the design and implementation of ad hoc harm reduction programs. The aim of this study was to quantitatively evaluate the prevalence of $\mathrm{HCV}$ among Iranian prisoners conducting a systematic review and meta-analysis.

\section{Methods}

A protocol for the current systematic review and metaanalysis was devised in accordance with the "Preferred Reporting Items for Systematic Reviews and MetaAnalyses" (PRISMA) guidelines [20] and prospectively registered in the PROSPERO database (identification ID: CRD42018082336).

Two authors independently searched for articles related to HCV infection among Iranian prisoners, mining scholarly databases such as Embase, PubMed/MEDLINE, ISI/ Web of Sciences, the Cochrane library, Scopus, CINAHL, and PsycINFO. Iranian bibliographic thesauri were searched as well (namely, Barakatns, MagIran, and SID), with no language restrictions or time filter (searches performed from inception until December 2017). The following strategy was used: ("Prevalence" OR" Epidemiology" OR "Frequency") AND ("Hepatitis C virus" OR "HCV" OR "Hepatitis "OR "Viral hepatitis") AND ("Prison" OR "Prisoner" OR "Inmates" OR "Jails" OR "Incarceration "OR "Pre-trial detention" OR "Juvenile detention facilities") AND "Iran." The reference list of each potentially eligible study was also reviewed and hand-searched for increasing the chance of getting relevant investigations.

\section{Inclusion criteria}

The inclusion criteria were as follows: (i) studies investigating the prevalence of $\mathrm{HCV}$ among Iranian prisoners; (ii) studies providing clear data and the possibility of calculating the prevalence; (iii) studies designed as observational studies (that is to say, a variety of designs were considered eligible including cross-sectional, casecontrol, prospective, or retrospective investigations); (iv) studies written in Persian and English; (v) studies that used validated diagnostic tests such as enzyme-linked immunosorbent assay (ELISA), polymerase-chain reaction (PCR), and recombinant immunoblot assay (RIBA); and (vi) studies that reported serological HCV data.

\section{Exclusion criteria}

Exclusion criteria were as follows (i) studies not conducted among Iranian prisoners; (ii) studies not reporting sufficient data to estimate the prevalence rate; (iii) studies designed as editorials, letters to editor, commentaries, expert opinions, case-series, case-reports, reviews, or conference abstracts; and (iv) studies reporting overlapping/updated data.

\section{Quality assessment}

The Newcastle Ottawa Scale (NOS) was used to assess the quality of the studies included. Based on the scores, studies were classified into three categories, namely, studies characterized by high risk (score in the range 13 ), moderate risk (score in the range 4-6), and low risk (score in the range 7-9).

\section{Data extraction}

Two authors independently extracted relevant information from the articles, including the surname of the first author, the location of the study, the year of publication, the sample size, the mean age of the participants, the diagnostic test used for $\mathrm{HCV}$ screening, the reported prevalence, the number of people living with $\mathrm{HCV}$, and the duration of imprisonment.

\section{Statistical analysis}

$\mathrm{HCV}$ prevalence with its $95 \%$ confidence interval (CI) was estimated using the DerSimonian-Laird random-effects model [21] with Freeman-Tukey double arcsine transformation [22]. To quantitatively assess heterogeneity among articles, $I^{2}$ test was used [23]. In case of statistically significant heterogeneity, in order to investigate its possible sources, meta-regression analyses were performed based on the year of publication, sample size, and the duration of the imprisonment. Furthermore, sensitivity analyses were performed to ensure stability of the findings. Egger's regression test was used to evaluate publication bias [24]. Based on sample size, quality of studies, and length of conviction, subgroup analyses were conducted. 
Figures with $p$ value $<0.05$ were considered statistically significant. Data were analyzed using STATA Ver.14 (Stata Corp, College Station, TX, USA).

\section{Results}

We identified an initial list of 273 articles, which resulted in 184 items after deleting 89 duplicates. By reviewing the title and/or abstract of these 184 articles, 145 unrelated articles were discarded. The full texts of 39 articles were reviewed, and finally 17 articles were selected based on inclusion and exclusion criteria. Figure 1 shows the process of searching and selecting studies.

In the current systematic review and meta-analysis, 18,693 prisoners were tested. Studies were published between 2004 and 2016. The sample size was between 101 and 8630. All studies used an ELISA diagnostic test for the evaluation of $\mathrm{HCV}$ antibodies. Concerning the quality of the studies, one study was found to be at high risk, six at moderate risk, and ten at low risk. Table 1 shows the main characteristics of the studies included.

Based on the random-effects model, the prevalence of $\mathrm{HCV}$ among Iranian prisoners was $28 \%$ (CI 95\% 21-36) with heterogeneity of $I^{2}=99.3 \%(p=0.00)$, as shown in Fig. 2.

To ensure the stability of the results, the sensitivity analysis was performed in order to examine the impact of each study on the overall prevalence. Before and after this analysis, the overall prevalence did not change and confirmed the stability of the findings (Fig. 3).

Subgroup analysis was performed based on variables such as quality, sample size, and length of conviction. Table 2 shows the results.

To evaluate possible heterogeneity sources among studies, meta-regression analyses were carried out based on the year of publication, sample size, and duration of imprisonment. Table 3 shows the results. The prevalence was borderline significant based both on the duration of conviction $(p=0.073)$ and the year of study publication $(p=0.074)$.

Various risk factors for $\mathrm{HCV}$ among Iranian prisoners have been reported including history of traditional phlebotomy, blood transfusions, tattooing, razor sharing, surgery, history of dental operations, sharing a syringe/needle, drug use, unprotected sex, sexually transmitted infections, alcohol consumption,

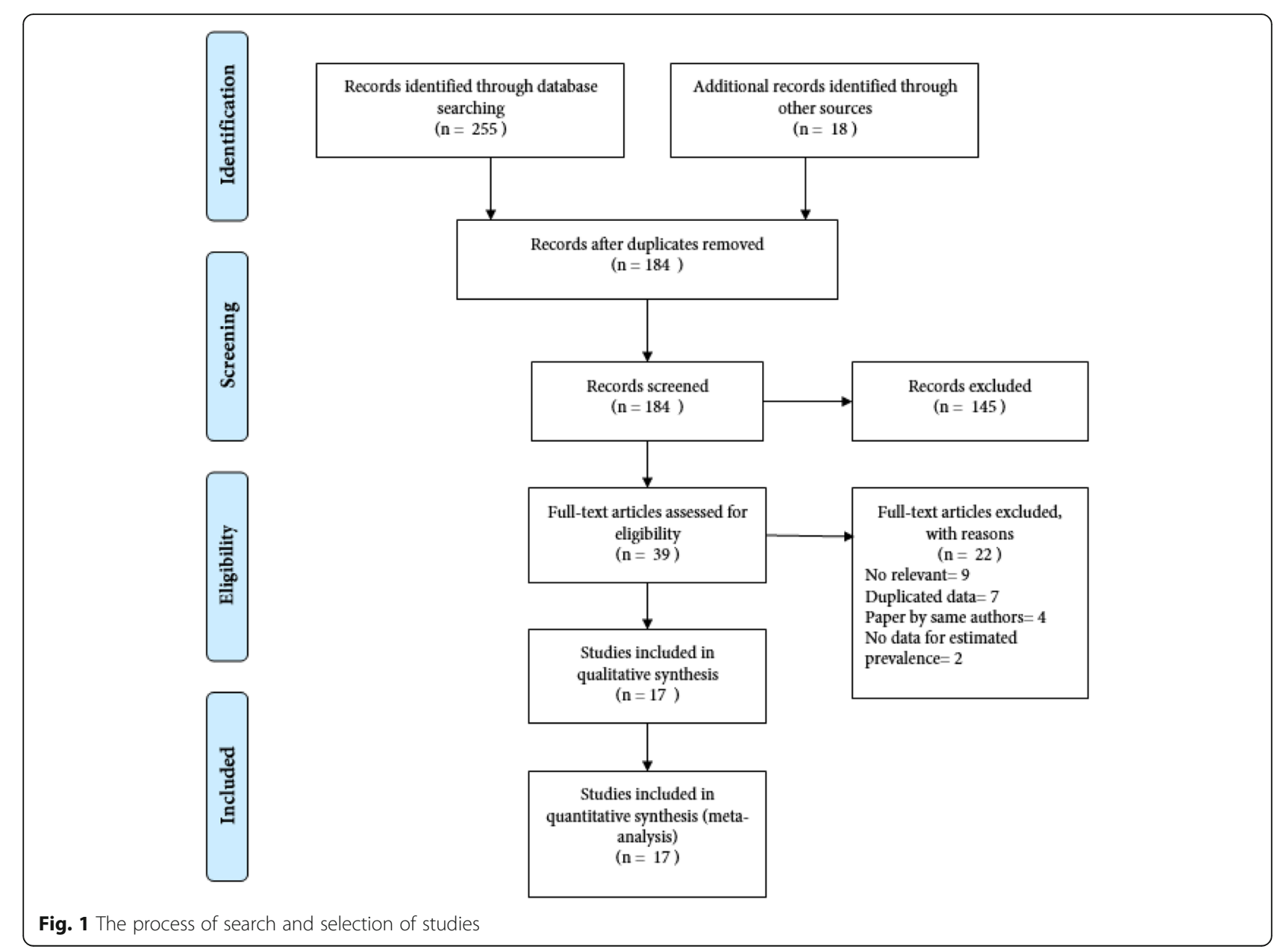


Table 1 The characteristics of studies included

\begin{tabular}{|c|c|c|c|c|c|c|c|}
\hline First author & Publication year & Province & Age $($ mean $\pm S D)$ & Sample size & Prevalence (\%) & Diagnostic test & Quality of studies \\
\hline Rowhani-Rahbar & 2004 & Razavi Khorasan & $32.8 \pm 8.9$ & 110 & 59.4 & ELISA & High \\
\hline $\begin{array}{l}\text { Mohammad } \\
\text { Alizadeh }\end{array}$ & 2005 & Hamedan & NA & 427 & 30 & ELISA & Medium \\
\hline Zakizadeh & 2006 & Mazandaran & NA & 312 & 30.80 & ELISA & High \\
\hline Mohtasham Amiri & 2007 & Guilan & $34.7 \pm 8.9$ & 460 & 45.40 & ELISA & Medium \\
\hline Pourahmad & 2007 & 3 provinces & NA & 1431 & 34.70 & ELISA & High \\
\hline Azarkar & 2007 & South Khorasan & $34.1 \pm 11.7$ & 400 & 7.80 & ELISA & High \\
\hline Asgari & 2008 & 10 provinces & NA & 8630 & 37.85 & ELISA & High \\
\hline Zakizad M & 2009 & Mazandaran & NA & 312 & 30.80 & ELISA & Medium \\
\hline Tajbakhsh & 2009 & $\begin{array}{l}\text { Chaharmahal and } \\
\text { Bakhtiari }\end{array}$ & 25.8 & 600 & 12.66 & ELISA & Low \\
\hline Davoodian & 2009 & Hormozgan & $35.4 \pm 8.4$ & 249 & 64.80 & ELISA & High \\
\hline Azarkar & 2010 & South Khorasan & $34.7 \pm 12$ & 358 & 8.10 & ELISA & High \\
\hline Kassaian & 2012 & Isfahan & 32.6 & 943 & 41.60 & ELISA & Medium \\
\hline Naghili & 2012 & East Azerbaijan & $31.3 \pm 10$ & 192 & 29 & ELISA & High \\
\hline Nokhodian & 2012 & Isfahan & $34.54 \pm 11.2$ & 163 & 7.40 & ELISA & High \\
\hline Ziaee & 2014 & South Khorasan & $34.7 \pm 11.4$ & 881 & 7.70 & ELISA & Medium \\
\hline Alasvand & 2015 & 6 Providences & $37 \pm 13$ & 2120 & 12.90 & ELISA & Medium \\
\hline Khajedaluee & 2016 & Razavi Khorasan & $53.37 \pm 54.9$ & 1114 & 24.50 & ELISA & High \\
\hline
\end{tabular}

\begin{tabular}{l} 
Study \\
ID \\
\hline Rowhani-Rahbar (2004) \\
Mohammad Alizadeh (2005) \\
Zakizadeh (2006) \\
Mohtasham Amiri (2007)
\end{tabular}

Fig. 2 The overall prevalence of HCV in prisoners Iranian based on the random-effects model 


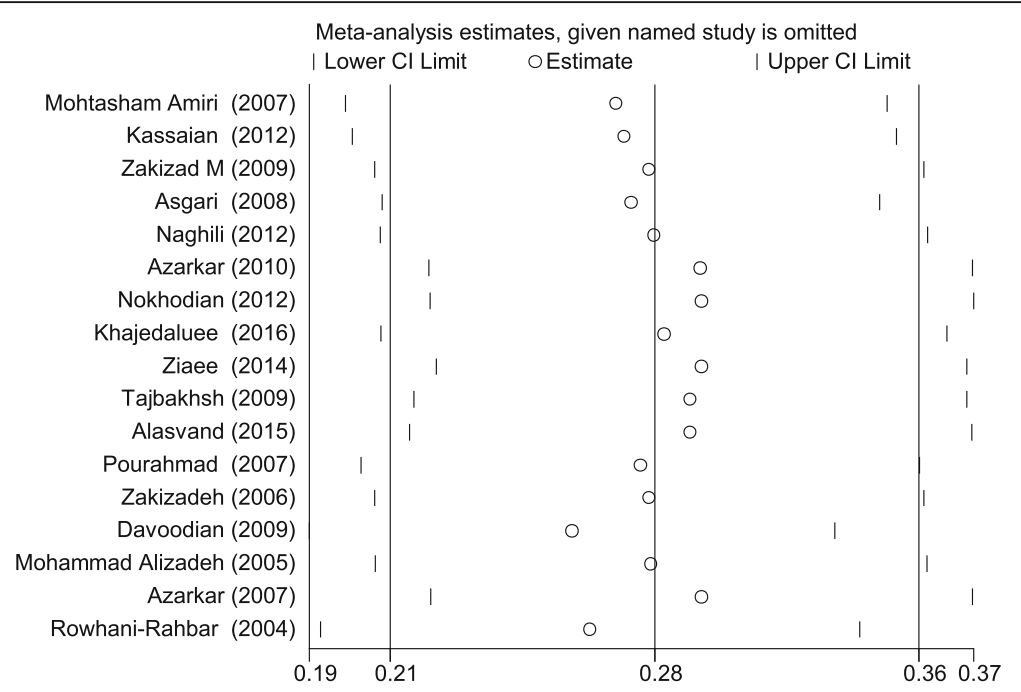

Fig. 3 The sensitivity analysis of the prevalence of HCV in prisoners Iranian based on the random-effect model

piercings, IDU, history of cupping, dialysis, and abortion. According to available data, we calculated the odds ratio (OR) for some of these factors (Table 4). Egger's regression test showed that there was no publication bias for the selected studies $(p=0.94)$ (Fig. 4).

\section{Discussion}

To the best of our knowledge, this study was the first and most comprehensive systematic review and metaanalysis that examined the prevalence of $\mathrm{HCV}$ among Iranian prisoners. Comprehensive search, the use of a checklist to assess the risk of studies, meta-regressions, sensitivity analysis, and publication bias assessment are among the strengths of this study.

$\mathrm{HCV}$ infection among inmates is a very serious problem that healthcare professionals in each country have to face. Given that there are about 10 million prisoners

Table 2 The results of subgroup analysis

\begin{tabular}{llll}
\hline Items & Prevalence 95\% Cl & $P^{2}(\%)$ & $P$ \\
\hline Quality of studies & & & \\
$\quad$ High & $13 \%(10-15)$ & - & - \\
$\quad$ Intermediate & $28 \%(16-40)$ & 99.1 & 0.00 \\
$\quad$ Low & $30 \%(20-40)$ & 99.2 & 0.00 \\
Sample size & & & \\
$\quad$ < 400 & $29 \%(16-43)$ & 98.6 & 0.00 \\
$>400$ & $27 \%(18-37)$ & 99.5 & 0.00 \\
Prisoner type & & & \\
$\quad$ Prisoners who inject drugs & $53 \%(42-64)$ & 94.6 & 0.00 \\
$\quad$ Prisoners who make use of drugs & $25 \%(11-38)$ & 97.5 & 0.00 \\
$\quad$ General (non-risk) & $19 \%(10-29)$ & 99.5 & 0.00 \\
\hline
\end{tabular}

around the world [25], attention to $\mathrm{HCV}$ prevention should be a public health priority in prisons in all developed and developing countries [26].

The findings of this study showed that the prevalence of $\mathrm{HCV}$ among Iranian prisoners was 28\% (CI 95\% 2136). This rate is higher than the prevalence in the general population [3]-0.6\% (CI 95\% 0.4-0.8\%) - and blood donors in Iran $[4]-0.5 \%$ (CI 95\% 0.4-0.6\%).

Compared to international studies, this rate is higher than the prevalence reported among prisoners in Italy (22.4\%) [27], in Brazil (2.4\%) [17], and in France $(4.8 \%)$ [28], and lower than the prevalence reported in California (34.3\%) [29] and in Indonesia (34.1\%) [30].

The causes of the difference in the prevalence among the studies carried out in different countries can be the type of prison population surveyed on the basis of significant risk factors such as IDU or the history of imprisonment and the conduct of high-risk sexual behaviors or other high-risk behaviors.

Prison health conditions vary in different parts of the world, and in many countries, there is still no definite policy to further improve the health of prisoners. On the other hand, it seems that screening conditions are not adequately provided for many of them at the time of imprisonment. The rules governing the legal system of the countries make it possible to create complex constraints for screening HCV. Sometimes, it is, indeed, difficult to reach a balance between ensuring adequate health standards and public safety, for example guaranteeing to prisoners continuity of healthcare and access to healthcare facilities (such as screening centers), before and during the transfer to custodial settings. On the other hand, there are also 
Table 3 The results of meta-regression

\begin{tabular}{lllll}
\hline Variables & Coef & SE & $P$ value & Adjusted $R^{2}(\%)$ \\
\hline Publication year & -0.022 & 0.011 & 0.074 & 14.30 \\
Sample size & 6.38 & 0.000 & 0.78 & -6.31 \\
Duration of incarceration (years) & 0.108 & 0.049 & 0.073 & 36.01 \\
\hline
\end{tabular}

financial problems in many sectors, such as the health and legal systems of the countries, which have led to the unfeasibility of screening all inmates [5]. Ensuring timely diagnostic tests for $\mathrm{HCV}$ would be, indeed, too much expensive. Even though numerous studies have assessed the cost-effectiveness of screening prisoners for $\mathrm{HCV}$, there is a dearth of information specifically concerning Iran. Furthermore, despite the fact that $\mathrm{HCV}$ is very common in prisoners and threatens their health status and conditions, there is still no screening program in Iran as well as in many countries [27]. Over the past years, policies have been developed in Iran to improve the health situation in Iran's prisons, but these efforts have not been sufficient and there is still a huge gap to be filled [31].

The findings of this study showed that the highest prevalence (53\%) was among prisoners who inject drugs. This finding is in line with other published investigations, including a Scottish study [32]. In a meta-analysis study that evaluates $\mathrm{HCV}$ in prisoners, the prevalence of IDU was estimated to be $64 \%$ [10]. The most important risk factor associated with $\mathrm{HCV}$ is, indeed, IDU, and this is a common danger in all prisons in the world. However, because of the lack of the implementation of proper harm reduction policies, it still remains a major problem for prisoners [33].

Studies show that IDU-related practices in Iran are on the rise [34]. Prisoners who inject drugs are more susceptible to infections such as HCV, HBV, and HIV than others [35]. Unfortunately, in recent decades, drug use has increased in Iran, and the pattern of drug use has changed, with an increasing trend in IDU [36]. In our findings, the OR for $\mathrm{HCV}$ for prisoners who inject drugs compared to other prisoners was 3.54. Findings from various studies indicate that prisoners are potentially susceptible to $\mathrm{HCV}[17,37,38]$. The OR in prisoners who had a history of sharing syringes/needles was 4.06 in comparison with other people. The lack of access to needle and syringe programs in prisons has led to a very high incidence of HCV [39]. Officials should identify prisoners who inject drugs to control $\mathrm{HCV}$ infection at the very beginning of their arrival, and provide them with sterile needles and syringes to prevent the spread of infection to other prisoners. The harm reduction-based training given to prisoners can also have an effective role in reducing the infection. In a study conducted in European countries, sterile syringes and needles were provided to prisoners, and they also received adequate training. Results showed that the use of syringes by other prisoners was reduced and no new cases HCV were reported [40].

Tattooing in prisons is another major health concern, due to the use of non-sterile devices leading to transmission of infections such as $\mathrm{HCV}, \mathrm{HBV}$, and HIV. In a meta-analysis study published in 2017, tattoos are considered as one of the most important risk factors for $\mathrm{HCV}$ transmission [41]. In the current study, those with a history of tattooing had a 2.59 higher risk than those without a history of tattooing. Two cohort studies in Australia have reported a significant relationship between tattooing and HCV infection [42, 43]. Prison authorities should provide harm reduction interventions for prisoners to help reduce any harms associated with these activities. A study conducted in seven European countries refers to the role of harm reduction programs and the improvement of health of prison population and the reduction of $\mathrm{HCV}$ [44].

The results of meta-regression analyses showed that there is a borderline significant relationship between the prevalence rate of $\mathrm{HCV}$ among Iranian prisoners and the year of studies publication. Since 2005, health policy- and decision-makers in the country have decided to formally adopt a harm reduction policy.

Table 4 Odds ratio (OR) for HCV-related risk factors

\begin{tabular}{lllll}
\hline Items & Number of studies & Odds ratio $(95 \% \mathrm{Cl})$ & $P^{2}(\%)$ & $P$ \\
\hline Injection of drugs & 8 & $3.54(2.28-5.49)$ & 88.6 & 0.00 \\
Tattooing & 6 & $2.59(1.74-3.86)$ & 01.7 & 9.00 \\
Having shared a syringe/needle & 4 & $4.06(0.70-23.51)$ & 5.4 & 0.00 \\
History of transfusion & 4 & $1.61(0.91-2.86)$ & 0.00 \\
Use of drugs & 3 & $1.16(0.38-3.54)$ & 94.3 \\
\hline
\end{tabular}




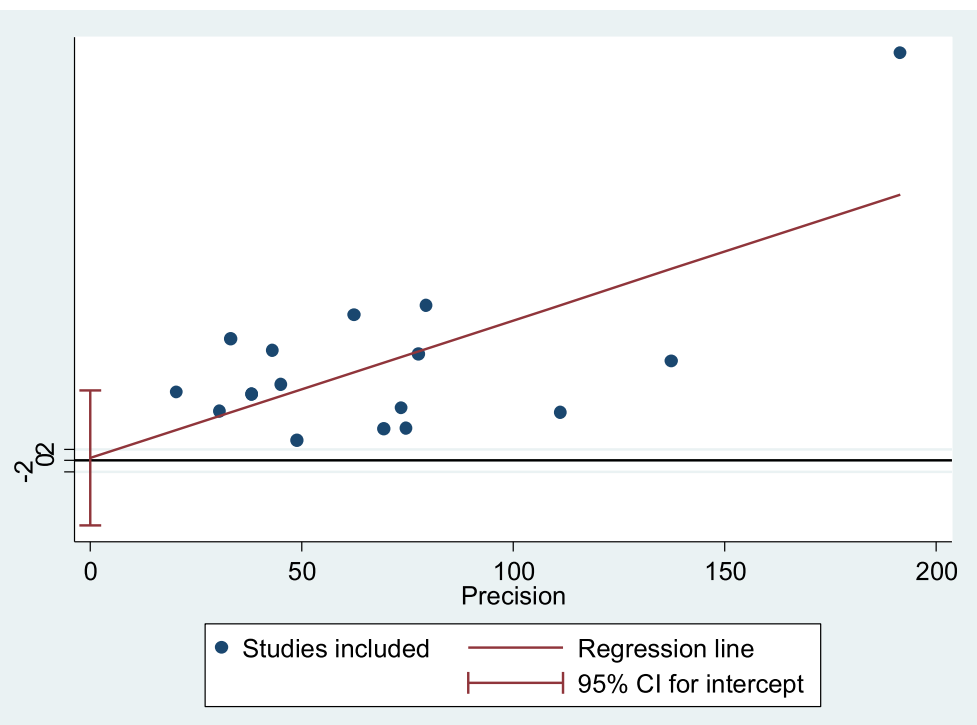

Fig. 4 The publication bias based on the Egger's test

Within this policy, prisoners who make use of drugs such as opioids can be legally treated with methadone. A strategy for making available sterile syringes and needles to prisoners who inject drugs was also considered [36]. However, despite the implementation of this policy, $\mathrm{HCV}$ infection among Iranian prisoners remains a challenge [45].

According to the findings of meta-regressions, the prevalence of $\mathrm{HCV}$ among Iranian prisoners has increased with time and length of conviction. The findings of a study carried out in Brazil seem to confirm this finding [17]. Prisoners are familiar with high-risk behaviors in prison over time, and in many cases, they may experience them. The results of a study in Ireland show that at least $21 \%$ of prisoners have experienced the first injection in jails [46].

However, this study has some limitations that should be mentioned: the major drawback is given by the presence of statistically significant heterogeneity among studies [47]. Furthermore, for many provinces of Iran, there is a dearth of information as no studies have been conducted. Moreover, data available did not allow comparisons to be performed based on gender.

\section{Conclusions}

In conclusion, health policy- and decision-makers in Iran need good evidence to improve public health status in prisons. The findings of our study showed that the prevalence of $\mathrm{HCV}$ among Iranian prisoners was $28 \%$. This prevalence is dramatically high. Managing this issue in Iran's prisons requires careful attention to the availability of health facilities and instruments, such as screening, and harm reduction policies, such as making needle and syringe programs available to prisoners. An integrated program of training for prisoners, prison personnel, and medical staff is also needed to improve the level of health condition in prisons.

\section{Abbreviations}

Cl: Confidence interval; ELISA: Enzyme-linked immunosorbent assay; HBV: Hepatitis B virus; HCV: Hepatitis C virus; HIV: Human immunodeficiency virus; IDU: Injecting drug use; NOS: The New Castle Ottawa Scale; OR: Odds ratio; PCR: Polymerase-chain reaction; PRISMA: Preferred Reporting Items for Systematic Reviews and Meta-Analyses; RIBA: Recombinant immunoblot assay

\section{Acknowledgements}

This study was part of a PhD thesis supported by the School of Health Management, Iran University of Medical Sciences, Iran (IUMS/SHMIS_1396/ 9423557001).

\section{Availability of data and materials}

The datasets generated and/or analyzed during the current study are not publicly available due the data being used for further research by the researchers and specified purposes within the ethics approval.

\section{Authors' contributions}

All authors were involved in the development of the design of the study. MB and HAG collected and analyzed the data. All authors drafted the manuscript. MB and HAG provided the overall methodological and content expertise guidance. All authors contributed to the drafting of the study and have read and approved the final manuscript.

Ethics approval and consent to participate Not applicable.

Competing interests

The authors declare that they have no competing interests. 


\section{Publisher's Note}

Springer Nature remains neutral with regard to jurisdictional claims in published maps and institutional affiliations.

\section{Author details}

'Department of Health Services Management, School of Health Management and Information Sciences, Iran University of Medical Sciences, Tehran, Iran. ${ }^{2}$ Health Management and Economics Research Center, Iran University of Medical Sciences, Tehran, Iran. ${ }^{3}$ Department of Health Sciences (DISSAL), School of Public Health, University of Genoa, Genoa, Italy.

\section{Received: 6 February 2018 Accepted: 17 April 2018}

\section{Published online: 09 May 2018}

\section{References}

1. Stanaway JD, Flaxman AD, Naghavi M, Fitzmaurice C, Vos T, Abubakar I, et al. The global burden of viral hepatitis from 1990 to 2013: findings from the Global Burden of Disease Study 2013. Lancet. 2016;388(10049):1081-8.

2. World Health Organization. Hepatitis C, fact sheet 2018. hhttp://www.who. int/mediacentre/factsheets/fs164/en/. Accessed 14 Apr 2018.

3. Mirminachi B, Mohammadi Z, Merat S, Neishabouri A, Sharifi AH, Alavian SH, et al. Update on the prevalence of hepatitis $C$ virus infection among Iranian general population: a systematic review and meta-analysis. Hepat Mon. 2017;17(2):e42291.

4. Khodabandehloo M, Roshani D, Sayehmiri K. Prevalence and trend of hepatitis $C$ virus infection among blood donors in Iran: a systematic review and meta-analysis. J Res Med Sci. 2013;18(8):674-82.

5. The global state of harm reduction 2016. Edited by Stone K. London: Harm Reduction International; 2016. https://www.hri.global/files/2016/11/14/ GSHR2016 14nov.pdf. Accessed 2 Apr 2018.

6. Fazel S, Baillargeon J. The health of prisoners. Lancet. 2011;377(9769):956-65.

7. Liao KF, Lai SW, Chang WL, Hsu NY. Screening for viral hepatitis among male non-drug-abuse prisoners. Scand J Gastroenterol. 2006;41(8):969-73.

8. Spaulding AC, Seals RM, McCallum VA, Perez SD, Brzozowski AK, Steenland NK. Prisoner survival inside and outside of the institution: implications for health-care planning. Am J Epidemiol. 2011;173(5):479-87.

9. Spaulding AC, Sharma A, Messina LC, Zlotorzynska M, Miller L, Binswanger IA. A comparison of liver disease mortality with HIV and overdose mortality among Georgia prisoners and releasees: a 2-decade cohort study of prisoners incarcerated in 1991. Am J Public Health. 2015;105(5):e51-e7.

10. Larney S, Kopinski H, Beckwith CG, Zaller ND, Jarlaid DD, Hagan H, et al. Incidence and prevalence of hepatitis $C$ in prisons and other closed settings: results of a systematic review and meta-analysis. Hepatol. 2013;58(4):1215-24

11. Vescio MF, Longo B, Babudieri S, Starnini G, Carbonara S, Rezza G, et al. Correlates of hepatitis $C$ virus seropositivity in prison inmates: a metaanalysis. J Epidemiol Community Health. 2008;62(4):305-13.

12. Imperial JC. Chronic hepatitis $C$ in the state prison system: insights into the problems and possible solutions. Expert Rev Gastroenterol Hepatol. 2010; 4(3):355-64

13. Dolan K, Wirtz AL, Moazen B, Ndeffo-Mbah M, Galvani A, Kinner SA, et al. Global burden of HIV, viral hepatitis, and tuberculosis in prisoners and detainees. Lancet. 2016;388(10049):1089-102.

14. Saiz de la Hoya P, Marco A, García-Guerrero J, Rivera A. Prevalhep study group. Hepatitis $C$ and B prevalence in Spanish prisons. Eur J Clin Microbiol Infect Dis 2011;30(7):857-862.

15. Niriella MA, Hapangama A, Luke HP, Pathmeswaran A, Kuruppuarachchi KA, de Silva HJ. Prevalence of hepatitis B and hepatitis $C$ infections and their relationship to injectable drug use in a cohort of Sri Lankan prison inmates. Ceylon Med J. 2015;60(1):18-20.

16. Keten D, Emin Ova M, Sirri Keten H, Keten A, Gulderen E, Tumer S, et al. The prevalence of hepatitis B and C among prisoners in Kahramanmaras, Turkey. Jundishapur J Microbiol. 2016;9(2):e31598.

17. Puga MA, Bandeira LM, Pompilio MA, Croda J, Rezende GR, Dorisbor LF, et al. Prevalence and incidence of HCV infection among prisoners in central Brazil. PLoS One. 2017;12(1):e0169195.

18. Alvarez KJ, Befus M, Herzig CT, Larson E. Prevalence and correlates of hepatitis $C$ virus infection among inmates at two New York State correctional facilities. J Infect Public Health. 2014;7(6):517-21.

19. Shaheen MA, Idrees M. Evidence-based consensus on the diagnosis, prevention and management of hepatitis C virus disease. World J Hepatol. 2015;7(3):616-62.
20. Liberati A, Altman DG, Tetzlaff J, Mulrow C, Gotzsche PC, loannidis JP, et al. The PRISMA statement for reporting systematic reviews and meta-analyses of studies that evaluate healthcare interventions: explanation and elaboration. BMJ. 2009:b2700:339.

21. DerSimonian R, Laird N. Meta-analysis in clinical trials revisited. Contemp Clin Trials. 2015;45(Pt A):139-45.

22. Freeman MF, Tukey JW. Transformations related to the angular and the square root. Ann Math Stats. 1950;21(4):607-11.

23. Higgins JP, Thompson SG, Deeks JJ, Altman DG. Measuring inconsistency in meta-analyses. BMJ. 2003;327(7414):557-60.

24. Egger M, Davey Smith G, Schneider M, Minder C. Bias in meta-analysis detected by a simple, graphical test. BMJ. 1997;315(7109):629-34.

25. Walmsley R. World prison population list. 2011.

26. Loxley W, Gray D, Wilkinson C, Chikritzhs T, Midford R, Moore D. Alcohol policy and harm reduction in Australia. Drug Alcohol Rev. 2005; 24(6):559-68.

27. Brandolini M, Novati S, De Silvestri A, Tinelli C, Patruno AFA, Ranieri R, et al. Prevalence and epidemiological correlates and treatment outcome of HCV infection in an Italian prison setting. BMC Public Health. 2013;13:981.

28. Semaille C, Le Strat Y, Chiron E, Chemlal K, Valantin MA, Serre P, et al. Prevalence of human immunodeficiency virus and hepatitis $C$ virus among French prison inmates in 2010: a challenge for public health policy. Euro Surveill. 2013;18(28):pii: 20524.

29. Fox RK, Currie SL, Evans J, Wright TL, Tobler L, Phelps B, et al. Hepatitis C virus infection among prisoners in the California state correctional system. Clin Infect Dis. 2005;41(2):177-86.

30. Prasetyo AA, Dirgahayu P, Sari Y, Hudiyono H, Kageyama S. Molecular epidemiology of HIV, HBV, HCV, and HTLV-1/2 in drug abuser inmates in central Javan prisons, Indonesia. J Infect Dev Ctries. 2013;7(6):453-67.

31. Roshanfekr P, Farnia M, Dejman M. The effectiveness of harm reduction programs in seven prisons of Iran. Iran J Public Health. 2013;42(12):1430-7.

32. Weinbaum C, Lyerla R, Margolis HS. Centers for Disease Control and Prevention. Prevention and control of infections with hepatitis viruses in correctional settings. Centers for disease control and prevention. MMWR Recomm Rep. 2003;52(RR-1):1-36; quiz CE1-4.

33. Zampino R, Coppola N, Sagnelli C, Di Caprio G, Sagnelli E. Hepatitis C virus infection and prisoners: epidemiology, outcome and treatment. World J Hepatol. 2015;7(21):2323-30.

34. Karamouzian M, Mirzazadeh A, Rawat A, Shokoohi M, Haghdoost AA, Sedaghat $A$, et al. Injection drug use among female sex workers in Iran: findings from a nationwide bio-behavioural survey. Int J Drug Policy. 2017;44:86-91.

35. May MT, Justice AC, Ingle SM, Smit C, Neau D, Guiguet M, et al. Injection drug use and Hepatitis C as risk factors for mortality in HIV-infected individuals: the antiretroviral therapy cohort collaboration. J Acquir Immune Defic Syndr. 2015;69(3):348-54.

36. Saberi Zafarghandi MB, Jadidi M, Khalili N. Iran's activities on prevention, treatment and harm reduction of drug abuse. Int J High Risk Behav Addict. 2015;4(4):e22863.

37. Peña-Orellana M, Hernández-Viver A, Caraballo-Correa G, Albizu-García CE. Prevalence of HCV risk behaviors among prison inmates: tattooing and injection drug use. J Health Care Poor Underserved. 2011;22(3):962-82.

38. Stone J, Martin NK, Hickman M, Aspinall E, Taylor A, Munro A, et al. Modelling the impact of incarceration and prison-based hepatitis $C$ virus ( $\mathrm{HCV}$ ) treatment on HCV transmission among people who inject drugs in Scotland. Addiction. 2017;112(7):1302-14.

39. Alavian SM. Hepatitis C infection in Iran; a review article. Iranian J Clin Infect Dis. 2009;4(1):47-59.

40. Dolan K, Rutter S, Wodak AD. Prison-based syringe exchange programmes: a review of international research and development. Addiction. 2003;98(2): $153-8$.

41. Khodadost M, Maajani K, Arabsalmani M, Mahdavi N, Tabrizi R, Alavian SM, et al. Is tattooing a risk factor for hepatitis c transmission?: an updated systematic review and meta-analysis. Hepat Mon. 2017;17(9):e14308.

42. Teutsch S, Luciani F, Scheuer N, McCredie L, Hosseiny P, Rawlinson W, et al. Incidence of primary hepatitis $C$ infection and risk factors for transmission in an Australian prisoner cohort. BMC Public Health. 2010;10:633.

43. Butler T, Kariminia A, Levy M, Kaldor J. Prisoners are at risk for hepatitis C transmission. Eur J Epidemiol. 2004;19(12):1119-22.

44. Sander G, Scandurra A, Kamenska A, MacNamara C, Kalpaki C, Bessa CF, et al. Overview of harm reduction in prisons in seven European countries. Harm Reduct J. 2016;13(1):28. 
45. Rahimi-Movaghar A, Amin-Esmaeili M, Shadloo B, Malekinejad M. Transition to injecting drug use in Iran: a systematic review of qualitative and quantitative evidence. Int J Drug Policy. 2015;26(9):808-19.

46. Allwright S, Bradley F, Long J, Barry J, Thornton L, Parry JV. Prevalence of antibodies to hepatitis B, hepatitis C, and HIV and risk factors in lrish prisoners: results of a national cross sectional survey. BMJ. 2000;321(7253):78-82.

47. Ioannidis JPA, Patsopolous NA, Rothstein HR. Reasons or excuses for avoiding meta-analysis in forest plots. BMJ. 2008;336(7658):1413-5.

Ready to submit your research? Choose BMC and benefit from:

- fast, convenient online submission

- thorough peer review by experienced researchers in your field

- rapid publication on acceptance

- support for research data, including large and complex data types

- gold Open Access which fosters wider collaboration and increased citations

- maximum visibility for your research: over $100 \mathrm{M}$ website views per year 